\title{
Common variants in genes coding for chemotherapy metabolizing enzymes, transporters, and targets: a case-control study of contralateral breast cancer risk in the WECARE Study
}

\author{
Jennifer D. Brooks $\cdot$ Sharon N. Teraoka $\cdot$ Leslie Bernstein • \\ Lene Mellemkjær · Kathleen E. Malone • Charles F. Lynch • \\ Robert W. Haile • Patrick Concannon - Anne S. Reiner - David J. Duggan • \\ Katherine Schiermeyer • The WECARE Study Collaborative Group • \\ Jonine L. Bernstein · Jane C. Figueiredo
}

Received: 31 July 2012/ Accepted: 21 May 2013/Published online: 18 June 2013

(C) The Author(s) 2013. This article is published with open access at Springerlink.com

\begin{abstract}
Purpose Women who receive chemotherapy for a first primary breast cancer have been observed to have a reduced risk of contralateral breast cancer (CBC), however, whether the genetic profile of a patient modifies this protective effect is currently not understood. The purpose of this study is to investigate the impact of germline genetic variation in genes coding for drug metabolizing enzymes,
\end{abstract}

Please see the "Appendix" section for the WECARE Study Collaborative Group members.

Electronic supplementary material The online version of this article (doi:10.1007/s10552-013-0237-6) contains supplementary material, which is available to authorized users.

J. D. Brooks $(\bowtie) \cdot$ A. S. Reiner · J. L. Bernstein

Department of Epidemiology and Biostatistics, Memorial Sloan-

Kettering Cancer Center, 307 E 63rd Street, 3rd Floor,

New York, NY, USA

e-mail: brooksj@mskcc.org

S. N. Teraoka $\cdot$ P. Concannon

Center for Public Health Genomics, University of Virginia,

Charlottesville, VA, USA

S. N. Teraoka $\cdot$ P. Concannon $\cdot$ K. Schiermeyer Department of Biochemistry and Molecular Genetics, University of Virginia, Charlottesville, VA, USA

L. Bernstein

Department of Population Sciences, Beckman Research Institute of the City of Hope, Duarte, CA, USA

L. Mellemkjær

Research Department II, Institute of Cancer Epidemiology,

Danish Cancer Society, Copenhagen, Denmark transporters, and targets on the association between chemotherapy and risk of CBC.

Methods From the population-based Women's Environment Cancer and Radiation Epidemiology (WECARE) Study, we included 636 Caucasian women with CBC (cases) and 1,224 women with unilateral breast cancer (controls). The association between common chemotherapeutic regimens, $\mathrm{CMF}$ and $\mathrm{FAC} / \mathrm{FEC}$, and risk of $\mathrm{CBC}$ stratified by genotype of 180 single nucleotide polymorphisms in 14 genes selected for their known involvement in metabolism, action, and transport of breast cancer chemotherapeutic agents, were determined using conditional logistic regression.

Results $\quad \mathrm{CMF}(\mathrm{RR}=0.5,95 \% \mathrm{CI} 0.4,0.7)$ and $\mathrm{FAC} / \mathrm{FEC}$ $(\mathrm{RR}=0.7,95 \% \mathrm{CI} 0.4,1.0)$ are associated with lower

\section{K. E. Malone}

Program in Epidemiology, Division of Public Health Science, Fred Hutchinson Cancer Research Center, Seattle, WA, USA

\section{F. Lynch}

Department of Epidemiology, University of Iowa College of Public Health, Iowa city, IA, USA

R. W. Haile · J. C. Figueiredo Department of Medicine, Division of Oncology, Stanford School of Medicine and the Stanford Cancer Institute, Stanford, CA, USA

\section{J. Duggan}

Genetic Basis of Human Disease Division, Translational

Genomic Research Institute, Phoenix, AZ, USA 
CBC risk relative to no chemotherapy in multivariableadjusted models. Here we show that genotype of selected genes involved in the metabolism and uptake of these therapeutic agents does not significantly alter the protective effect of either CMF or FAC/FEC on risk of CBC.

Conclusion The results of this study show that germline genetic variation in selected gene does not significantly alter the protective effect of CMF, FAC, and FEC on risk of $\mathrm{CBC}$.

Keywords Genetic variation - Chemotherapy - CMF . Contralateral breast cancer

\section{Background}

Adjuvant chemotherapy is indicated in the clinical management of most premenopausal women and postmenopausal women with ER- tumors, improving disease-free and overall survival [1-5]. Studies have also shown that the risk of asynchronous contralateral breast cancer (CBC) is lower among individuals who receive chemotherapy for treatment of their first primary breast cancer [6, 7], with overall CBC risk reductions of 30-80\% reported in observational studies of women treated for breast cancer [7-12].

Germline genetic variation in drug metabolizing enzymes and transporters is thought to contribute to the observed inter-individual variation in treatment efficacy $[13,14]$. The extent to which variation in these genes modifies the association between chemotherapy and risk of $\mathrm{CBC}$ is not known. Candidate genes can be classified into three main categories: phase I enzymes [e.g., cytochrome P450 (CYP) enzymes], phase II conjugation enzymes [e.g., glutathione S-transferases (GSTs)], and drug transporters (e.g., ABCB1). Together, these proteins influence the bioactivation, inactivation, and detoxification of a wide range of therapeutics [13]. The impact of variation in these genes on the association between chemotherapy and risk of $\mathrm{CBC}$ is not known.

In this study, we examined the impact of common single nucleotide variation in genes coding for drug metabolizing enzymes (CYP1A1, CYP1B1, CYP2A6, CYP2B6, CYP2C9, CYP2D6, CYP3A4, CYP3A5, GSTM1, GSTM2, GSTP1), targets (DHFR, MTHFR), and transporters (ABCBI), known to be involved in the metabolism and action of drugs commonly used in polychemotherapy regimens for breast cancer (e.g., cyclophosphamide, anthracyclines, and antimetabolites) $[14,15]$, on risk of CBC in the Women's Environment Cancer and Radiation Epidemiology (WECARE) Study, a population-based case-control study of women with $\mathrm{CBC}$ (cases) and unilateral breast cancer (UBC) (controls).

\section{Methods}

Study population

Participants were identified through five population-based cancer registries: Los Angeles County Cancer Surveillance Program; Cancer Surveillance System of the Fred Hutchinson Cancer Research Center (Seattle); State Health Registry of Iowa; and the Cancer Surveillance Program of Orange County/San Diego-Imperial Organization for Cancer Control (Orange County/San Diego). These cancer registries contribute to the National Cancer Institute Surveillance, Epidemiology, and End Results (SEER) program. The fifth registry from which subjects were recruited was the Danish Breast Cancer Cooperative Group Registry, supplemented by data from the Danish Cancer Registry [16].

Details of CBC case and UBC control eligibility have been described previously [16]. Briefly, cases were women diagnosed prior to age 55 years, from 1985 to 2000, with invasive breast cancer that had not spread beyond regional lymph nodes. This had to be followed by a second in situ or invasive breast cancer diagnosed in the contralateral breast at least 1 year later. The 'at-risk' interval was defined as starting at the time of first breast cancer diagnosis and ending at reference date, that is, date of the second breast cancer diagnosis in cases (reference date) or the corresponding date in matched controls. Two controls were individually matched to each case on year of birth (in 5-year strata), year of diagnosis (in 4-year strata), registry region, and race/ethnicity. All women had to be alive at the time of contact and able to complete a telephone interview and donate a blood sample. Counter-matching based on registry-reported radiation treatment status was used to improve the statistical efficiency of the study design. Thus, for each radiation exposed case, one radiation exposed control and one unexposed control were selected from the relevant stratum; and for each unexposed case, two radiation exposed controls were selected [16].

Across the five cancer registries, 708 cases and 1,399 controls completed the study interview and provided a blood sample. Four individuals were excluded from the current analysis because they did not consent to genotyping beyond the initial ATM, BRCA1, and BRCA2 mutation screening. To minimize the potential influence of ancestral differences in genotype frequencies, all analyses were restricted to Caucasian women $(n=1,933)$ as recorded by the cancer registry. Further exclusions were made after genotyping (see below).

\section{Data collection}

The data collection protocol was approved by the institutional review board at each of the participating centers and 
by the Ethical Committee System in Denmark. Each woman provided written informed consent. Details of the study questionnaire have been published previously and included questions about known breast cancer risk factors [16]. Medical records, pathology reports, and hospital charts, in addition to self-reported data (collected during the telephone interview), were used to collect detailed treatment information (surgery, chemotherapy, hormonal therapy, radiation therapy) on the first primary breast cancer as well as during the at-risk period. Information collected on chemotherapy and hormonal therapy included dates of administration, reason for treatment (e.g., primary disease, recurrence), and type of drug. The most common chemotherapeutic regimens received by women in the WECARE Study population were cyclophosphamide (CTX), methotrexate (MTX), 5-fluorouracil (5FU) (CMF) (63\% of women treated with chemotherapy were treated with $\mathrm{CMF}$ ) and 5FU, doxorubicin (Adriamycin ${ }^{\circledR}$ ), CTX (FAC) or 5FU, epirubicin, CTX (FEC) (19\% of women treated with chemotherapy were treated with $\mathrm{FAC} / \mathrm{FEC}$ ) (Table 1). All other drug combinations were coded as 'other' chemotherapy. For the current analyses, a woman was classified as having received CMF or FAC/FEC if she received these combinations of drugs any time during her treatment for a first primary breast cancer and prior to the reference date.

\section{Genotyping}

Genes were selected for their known involvement in the metabolism, action, and transport of chemotherapeutic agents commonly used to treat breast cancer. A list of genes and their associated drugs can be found in Table 2 .

DNA was prepared from blood samples by red cell lysis and standard methods of phenol/chloroform extraction. Samples were genotyped with Illumina's HumanOmni1Quad BeadChip (Illumina Inc., San Diego, CA, USA) as part of the WECARE Study's GWAS effort. Default Omni1-Quad cluster definitions supplied by Illumina were used to call genotypes, and single nucleotide polymorphisms (SNPs) with GenTrain scores $<0.36$ were considered 'no calls,' and samples with call rates $<95 \%$ were excluded in addition to other exclusion criteria described below. Each 96 well plate included one inter-plate positive quality control sample (NA06990-Coriell Cell Repositories). In addition, 38 blinded and 46 unblinded quality controls replicates from the study sample were genotyped. Concordance rates for both the Coriell and study sample replicates were high: $>99.99 \%$.

Additional genotyping in these genes was performed to broaden gene coverage. SNP lists from the HapMap project (http://hapmap.ncbi.nlm.nih.gov/) were imported into Tagger (in Haploview) [17], and haplotype tagging SNPs
(tagSNPs) were selected based on patterns of linkage disequilibrium (LD) with boundaries suggested by Gabriel et al. [18]. tagSNPs were selected based on pairwise tagging with a minimum $r^{2}$ of 0.90 . Multiplex SNP genotyping was carried out using the Illumina Golden Gate ${ }^{\mathrm{TM}}$ assay on custom BeadChips (Illumina Inc., San Diego, CA, USA). Laboratory methods and sample control measures have been described previously [19].

The CYP2D6*4 (rs3892097) variant was genotyped by a modified MGB Eclipse probe assay (Epoch Biosciences, ELITech Group, Paris, France). The outer primers designed to exclude pseudogenes were $5^{\prime}$ AGCCTGCCCCAGCCA AGGGAGC $3^{\prime}$ and $5^{\prime}$ CTCGGTCTCTCGCTCCGCAC $3^{\prime}$. The internal primers were designed by Epoch Biosciences to encompass the SNP: $5^{\prime}$ AATAAATCATAACCCCTTA CCCGCATCTC $3^{\prime}$ and $5^{\prime}$ GATCACGTTGCTCACGGCT TTGTCCAAGAG $3^{\prime}$. DNA was amplified using the standard Eclipse protocol except that in the first 15 of 50 cycles, and the annealing temperature was increased by ten degrees to $68{ }^{\circ} \mathrm{C}$. This method resulted in $100 \%$ concordance of genotypes among the $24 \%$ blinded, re-sampled DNAs. A subset of samples (17\%) was confirmed by a second method, allele-specific tetra-primer PCR, and separation of the allele-specific fragment sizes on $1 \%$ agarose [20].

Quality control steps applied to the genome-wide association study (GWAS) data lead to further subject exclusions: (a) Women with SNP call rates $<95 \%$ were excluded $(n=22)$; (b) Population stratification was investigated using EIGENSTRAT [21]; using the first two principal components, 9 outliers with significant African or Chinese ancestry were identified for exclusion; and (c) 14 additional participants were excluded due to incomplete matched sets. Identity by descent was examined using PLINK [22] identifying 3 pairs of sisters, including one pair of identical twins. These women were not excluded from the analysis. An additional 28 subjects were excluded because they had $>5 \%$ missing genotypes on the SNP BeadChips. Analyses are based on the remaining 1,860 participants (636 CBC cases and 1,224 UBC controls) with genotype data from both the Omni1-Quad and custom bead chips platforms.

Within the selected genes of interest, 260 SNPs were genotyped on the OMNI platform, 27 SNPs on the SNP BeadChip, and rs3892097 (CYP2D6*4) on a modified MGB Eclipse probe assay (for a total of 287 genotyped SNPs). SNPs with $>10 \%$ missing $(n=16)$ and those that were monomorphic $(n=87)$ were excluded. Although Hardy-Weinberg equilibrium may not strictly apply since all participants in the study were affected with breast cancer, 4 SNPs deviating from Hardy-Weinberg equilibrium $(p<0.001)$ were also excluded. This left 180 SNPs in or near 14 genes to be included in the analyses: 1 SNP in 
Table 1 Characteristics of selected cases (women with asynchronous CBC) and controls (women with UBC only) from the WECARE Study population

\begin{tabular}{|c|c|c|c|c|c|}
\hline Variable & Median (range) & $\begin{array}{l}\text { Cases }(\mathrm{CBC}) \\
\text { Median (ran }\end{array}$ & & & $\begin{array}{l}\text { UBC) } \\
\text { ange) }\end{array}$ \\
\hline Age at first diagnosis (years) & $46(23-55)$ & $46(24-55)$ & & & \\
\hline Age at reference date (years) & $51(27-71)$ & $51(27-71)$ & & & \\
\hline Length of at-risk period (years) ${ }^{a}$ & $4(1-16)$ & $4(1-16)$ & & & \\
\hline Variable & Level & Case & & Contro & \\
\hline & & $n$ & $\%$ & $n$ & $\%$ \\
\hline Study site & Iowa & 107 & 17 & 206 & 17 \\
\hline & Orange and San Diego Counties & 105 & 17 & 202 & 17 \\
\hline & Los Angeles & 154 & 24 & 290 & 24 \\
\hline & Seattle & 94 & 15 & 187 & 15 \\
\hline & Denmark & 176 & 28 & 339 & 28 \\
\hline Year of first diagnosis & $1985-1988$ & 221 & 35 & 422 & 35 \\
\hline & 1989-1992 & 214 & 34 & 414 & 34 \\
\hline & 1993-1996 & 160 & 25 & 309 & 25 \\
\hline & $1997+$ & 41 & 6 & 79 & 6 \\
\hline Chemotherapy & No & 355 & 56 & 562 & 46 \\
\hline & Yes & 281 & 44 & 662 & 54 \\
\hline $\mathrm{CMF}$ & Yes & 155 & 24 & 439 & 36 \\
\hline FAC/FEC & Yes & 61 & 10 & 119 & 10 \\
\hline Tamoxifen treatment & No & 485 & 76 & 861 & 70 \\
\hline & Yes & 139 & 22 & 338 & 28 \\
\hline & Unknown & 12 & 2 & 25 & 2 \\
\hline Radiation treatment & Never & 322 & 51 & 240 & 20 \\
\hline & Ever & 314 & 49 & 984 & 80 \\
\hline Histology of first breast cancer & Lobular & 82 & 13 & 120 & 10 \\
\hline & Other & 554 & 87 & 1,104 & 90 \\
\hline Stage of first breast cancer & Localized & 456 & 72 & 793 & 65 \\
\hline & Regional & 180 & 28 & 431 & 35 \\
\hline ER Status of first breast cancer ${ }^{b}$ & Positive & 302 & 47 & 656 & 54 \\
\hline & Negative & 165 & 26 & 288 & 24 \\
\hline & Other & 169 & 27 & 280 & 23 \\
\hline PR Status of first breast cancer ${ }^{b}$ & Positive & 252 & 40 & 536 & 44 \\
\hline & Negative & 144 & 23 & 270 & 22 \\
\hline & Other & 240 & 38 & 418 & 34 \\
\hline Menopausal status/age at menopause at first diagnosis & Premenopausal & 468 & 74 & 919 & 75 \\
\hline & Postmenopausal age $<45$ & 84 & 13 & 183 & 15 \\
\hline & Postmenopausal age $\geq 45$ & 83 & 13 & 118 & 10 \\
\hline & Unknown & 1 & 0.2 & 4 & 0 \\
\hline Family history of breast cancer & None & 420 & 66 & 954 & 78 \\
\hline & $\geq 1$ First-degree relative & 205 & 32 & 246 & 20 \\
\hline & Adopted & 11 & 2 & 24 & 2 \\
\hline
\end{tabular}

Includes Caucasian women with SNP call rates $\geq 95 \%$, without significant African or Asian ancestry with complete information on tamoxifen treatment and genotype data from both the Omni1-Quad and custom BeadChip platforms (636 CBC cases and 1,224 UBC controls)

$\mathrm{CBC}=$ asynchronous contralateral breast cancer; $\mathrm{UBC}=$ unilateral breast cancer; $\mathrm{CMF}=$ cyclophosphamide, methotrexate, 5-fluorouracil; $\mathrm{FAC} /$ $\mathrm{FEC}=$ cyclophosphamide, doxorubicin/epirubicin, 5-fluorouracil chemotherapy; $\mathrm{ER}=$ estrogen receptor, $\mathrm{PR}=$ progesterone receptor

${ }^{a}$ Beginning 1 year after first diagnosis extending to the reference date (date of second diagnosis in cases)

${ }^{b}$ Refers to receptor status of the first primary breast cancer. The 'other' category consists of women for whom no lab test was given, the test was given and the results are unknown or the test was given and the results were borderline 
Table 2 Candidate genes coding for selected drug metabolizing enzymes, targets, and transporters

\begin{tabular}{|c|c|}
\hline Drugs & Genes of interest \\
\hline Cyclophosphamide & $\begin{array}{l}\text { CYP1A1, CYP1B1, CYP2A6, } \\
\text { CYP2B6, CYP2C9, CYP2D6, } \\
\text { CYP3A4, CYP3A5, GSTM1, } \\
\text { GSTM2, GSTP1 }\end{array}$ \\
\hline Methotrexate, 5-fluorouracil & DHFR, MTHFR, ABCB1 \\
\hline $\begin{array}{l}\text { Doxorubicin (adriamycin), } \\
\text { epirubicin }\end{array}$ & GSTM1, GSTM2, GSTP1, ABCB1 \\
\hline
\end{tabular}

CYP1A1, 4 in $C Y P 1 B 1,2$ in $C Y P 2 A 6,6$ in $C Y P 2 B 6,4$ in CYP2C9, 9 in $C Y P 2 D 6,26$ in CYP3A4, 33 in CYP3A5, 13 in DHFR, 3 in GSTM1, 1 in GSTM2, 22 in GSTP1, 54 in $M T H F R$, and 2 in $A B C B 1$ (Online Resource 1).

\section{Statistical analysis}

In analyses examining the impact of genotype on the association between CMF and risk of CBC, the chemotherapy regimen variable was coded as $\mathrm{CMF}$, other chemotherapy regimens, and no chemotherapy. Similar coding was used for FAC/FEC analyses. In all instances, the comparison group was women who did not receive chemotherapy. In the CMF analyses, FAC/FEC was coded as 'other chemotherapy' and vice versa. SNPs in genes that code for enzymes involved in the metabolism or action of cyclophosphamide, methotrexate, 5-fluorouracil, or doxorubicin/epirubicin were included in the analyses (Table 2). Based on the combination of drugs used in either regimen, the same SNPs were included in the CMF and FAC/FEC analyses.
Rate ratios (RR) and $95 \%$ confidence intervals (CI) were estimated using conditional logistic regression to examine the association between chemotherapeutic regimen (CMF or FAC/FEC) and risk of $\mathrm{CBC}$, stratified by genotype for each SNP using the dominant model [0 (homozygous wild-type), 1 (heterozygous and homozygous variant)]. Models were run adjusting for age at first breast cancer diagnosis and included an 'offset term' (i.e., log weight 'covariate' in the model where the coefficient of this log weight is fixed at one [16]), taking into account the sampling probabilities of the counter-matching. Multivariable adjusted models were also run including adjustment for age at first diagnosis, family history, stage and histology of first primary breast cancer, and other treatments (hormonal therapy and radiation therapy). The likelihood ratio test was used to test for heterogeneity of treatment effect across genotypes.

Age and multivariable-adjusted [as described above] analyses were also conducted to confirm the association between chemotherapy and CBC risk in the subgroup of women included in the current analyses [1,860 (88\%) of the 2,107 total number of women in the WECARE Study].

A conservative Bonferroni correction was used to determine the multiple comparison cut-point $(\alpha=0.0003$, obtained from $(0.05 / 180$ SNPs) at which results were considered statistically significant. All analyses were conducted using SAS 9.2 (SAS Institute Inc., Cary, NC, USA). Figures were generated using Microsoft ${ }^{\circledR}$ Excel 2007.

\section{Results}

Selected characteristics of the eligible WECARE Study population are shown in Table 1. Cases and controls were
Fig. $1 \log _{10} p$ value for heterogeneity (multivariableadjusted models) of the association between $\mathrm{CMF}$ treatment regimen and risk of CBC for 180 SNPs. ${ }^{\mathrm{a}}$ The dashed line shows the $p$ value cut-off of 0.05 and the solid line the Bonferroni-corrected $p$ value cut-off of 0.0003

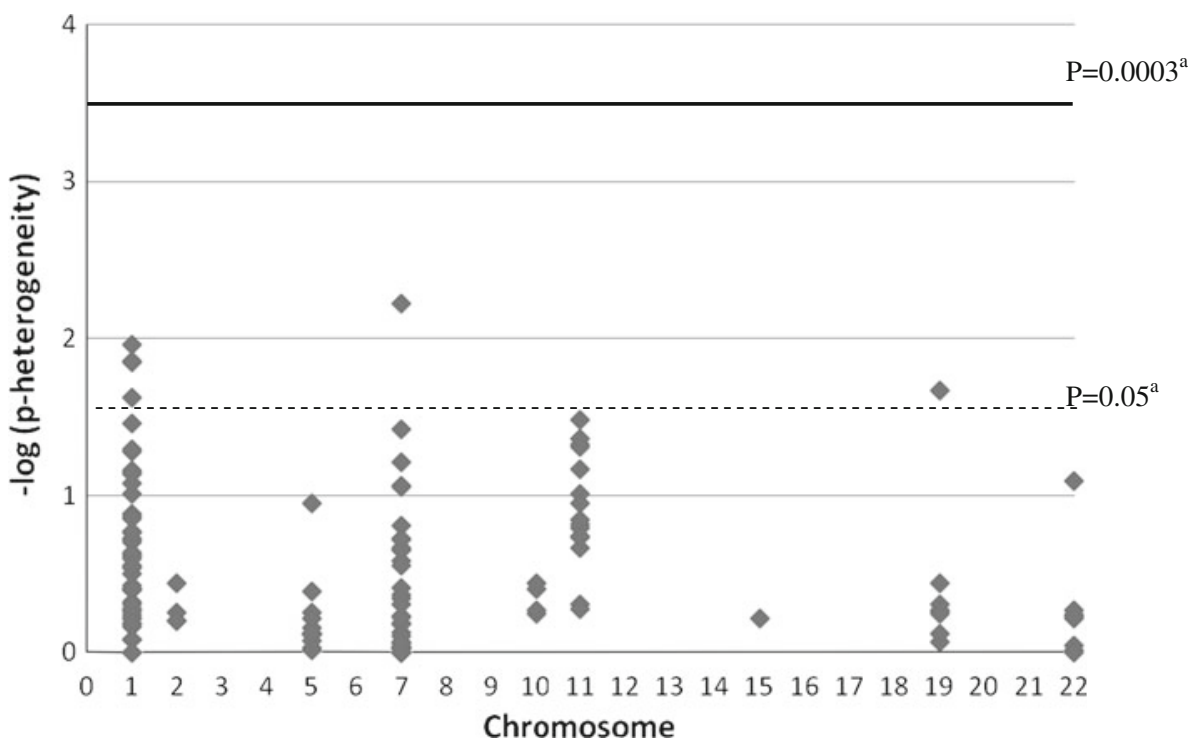


Fig. $2 \log _{10} p$ value for heterogeneity (multivariableadjusted models) of the association between FAC/FEC treatment regimen and risk of CBC for 180 SNPs. ${ }^{\mathrm{a}}$ The dashed line shows the $p$ value cut-off of 0.05 and the solid line the Bonferroni-corrected $p$ value cut-off of 0.0003

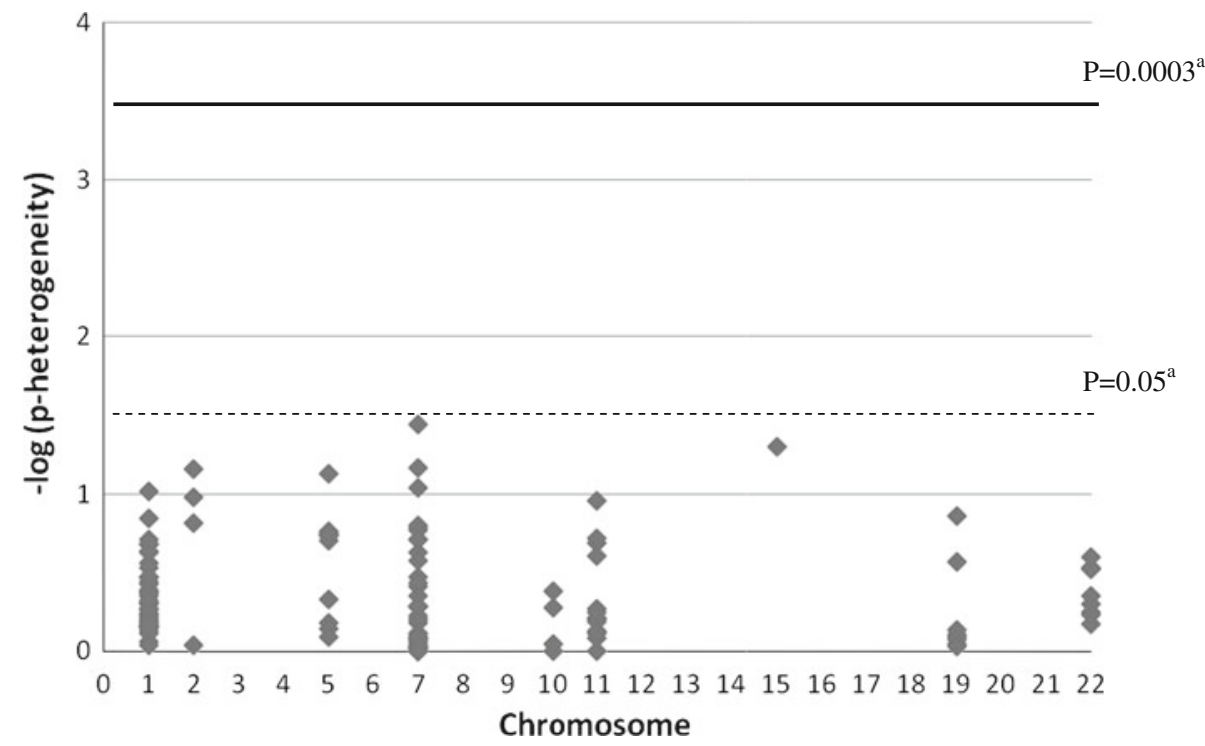

similar for all matching characteristics. In multivariableadjusted models, both CMF ( $\mathrm{RR}=0.5,95 \% \mathrm{CI} 0.4,0.7$ ) and $\mathrm{FAC} / \mathrm{FEC}(\mathrm{RR}=0.7,95 \% \mathrm{CI} 0.4,1.0)$ are associated with lower risk of $\mathrm{CBC}$ relative to no chemotherapy. In stratified analyses using the dominant model, chemotherapy was protective with respect to risk of $\mathrm{CBC}$, regardless of genotype. Figures 1 and 2 show the $-\log _{10}(p$ for heterogeneity) for each SNP, grouped by chromosome, and for CMF and FAC/FEC analyses, respectively. Results showing the association between CMF and FAC/FEC treatments and risk of CBC stratified by genotype for all SNPs did not differ in age and multivariable adjusted models and can be found in Online Resource 2 and Online Resource 3, respectively. Findings from some commonly studied candidate SNPs are reported below.

In multivariable-adjusted models, the variants rs1801133 and rs1801131 in MTHFR, known to be associated with altered enzyme activity, did not significantly modify the reduction in CBC risk seen with CMF $(\mathrm{RR}=0.5,95 \%$ CI $0.3,0.8$ in rs 1801133 wild-type compared to $\mathrm{RR}=0.7,95 \% \mathrm{CI} 0.4,1.1$ in women who are heterozygous or homozygous for the rs 1801133 variant, $p$ for heterogeneity $=0.29$, and $\mathrm{RR}=0.8,95 \%$ CI $0.5,1.3$ in rs1801131 wild-type compared to $\mathrm{RR}=0.4,95 \% \mathrm{CI}$ 0.3, 0.7 in women who are heterozygous or homozygous for the rs 1801131 variant, $p$ for heterogeneity $=0.01$ ).

Rs1695 in GSTP1 also did not significantly modify the effect of chemotherapy on risk of CBC $(\mathrm{RR}=0.5,95 \%$ CI $0.3,0.9$ in rs 1695 wild-type compared to $\mathrm{RR}=0.7$, $95 \%$ CI $0.4,1.0$ in women who are heterozygous or homozygous for the rs1695 variant, $p$ for heterogeneity $=0.49$ in women receiving $\mathrm{CMF}$, and $\mathrm{RR}=0.9,95 \% \mathrm{CI}$ $0.5,1.8$ in rs1695 wild-type compared to $\mathrm{RR}=0.6,95 \%$ CI $0.3,1.1$ in women who are heterozygous or homozygous for the rs 1695 variant, $p$ for heterogeneity $=0.25$ in women receiving $\mathrm{FAC} / \mathrm{FEC}$ ).

Similarly, the association between chemotherapy and risk of CBC did not differ when stratified by $C Y P 3 A 4 * 1 B$ (rs2740574) genotype ( $\mathrm{RR}=0.6,95 \% \mathrm{CI} 0.4,0.9$ in rs 2740574 wild-type compared to $\mathrm{RR}=1.0,95 \%$ CI 0.4 , 2.7 in women who are heterozygous or homozygous for the rs2740574 variant, $p$ for heterogeneity $=0.22$ in women receiving $\mathrm{CMF}$, and $\mathrm{RR}=0.7,95 \% \mathrm{CI} 0.4,1.2$ in rs2740574 wild-type compared to RR $=0.7,95 \%$ CI 0.2 , 2.6 in women who are heterozygous or homozygous for the rs2740574 variant, $p$ for heterogeneity $=0.91$ in women receiving $\mathrm{FAC} / \mathrm{FEC}$ ).

\section{Discussion}

Chemotherapy reduces the risk of $\mathrm{CBC}$ [6-12]; however, the impact of germline genetic variation in drug metabolizing enzymes, targets, and transporters on this association has not been investigated. Consistent with our prior publication [8], chemotherapy was associated with a lower risk of CBC. Here, we show that variation in these selected genes did not alter this protective effect of chemotherapy on risk of CBC in a large, well-characterized study population. This is the first study to specifically address the association between genetic variants, chemotherapy, and risk of $\mathrm{CBC}$ and to show that chemotherapy is protective with respect to $\mathrm{CBC}$ risk, despite differences in the genetic profiles of the genes investigated here.

CTX, a widely used nitrogen mustard alkylating agent, is a component of both the CMF and FAC/FEC regimens and the most common agent received by the WECARE Study population. The pharmacokinetics of CTX are highly 
variable (reviewed in [23]). CTX is administered as an inactive pro-drug that requires metabolization by several cytochrome P450 enzymes including CYP2B6 [24], CYP2C9 [25], and CYP3A4 [26] with minor contributions from CYP2A6, CYP2C8, and CYP2C19 (reviewed in [27]), to its active metabolite 4-hydroxycyclophosphamide (4OHCTX), which is further detoxified by the phase II enzymes GSTs [28]. Patient characteristics, including weight and age, influence treatment efficacy, but some variation in clinical response may also be attributed to germline genetic variation in these phase I and phase II enzymes. Comparison between studies is complicated by the inclusion of different SNPs in different genes. Prior studies have shown that some variants in CYPs and GSTs can alter the pharmacokinetics of CTX metabolism [27, 29, 30] and influence clinical response and toxicity of CTXbased chemotherapies [31-38]. Other studies have found no association between genetic variants in these genes and CTX pharmacokinetics [39] or outcome [40]. Our study of some of these same variants found that genotype did not alter the association between CTX-based chemotherapies and risk of $\mathrm{CBC}$.

MTX and 5FU are antimetabolites that interfere with cellular metabolism. MTX acts by inhibiting two enzymes: dihydrofolate reductase (DHFR) and thymidylate synthase (TS). 5FU, as an anti-folate metabolite, has several cytotoxic mechanisms [41]. MTHFR is a central regulatory enzyme in folate metabolism and has known variants that impact enzyme function (e.g., rs1801131, rs1801133). These variants have been shown to alter methotrexate toxicity (reviewed in [42]). Variation in MTHFR has also been shown to increase sensitivity to $5 \mathrm{FU}$ and decrease sensitivity to MTX in breast cancer cell lines [43], increase risk of mortality after chemotherapy for breast cancer [44], and reduce 5FU response in colorectal cancer [45-47]. Paré et al. [48] found no association between variation in MTHFR and disease-free survival in breast cancer patients who received $\mathrm{CMF}$ or FEC. Our study also found that variants in $M T H F R$, including those known to influence enzyme function, did not modify the effect of chemotherapy on risk of $\mathrm{CBC}$.

Anthracyclines [e.g., doxorubicin, epirubicin (the $4^{\prime}$ epimer of doxorubicin)] have multiple anti-cancer mechanisms including DNA intercalation, generation of freeradicals, and disruption of topoisomerase II-mediated DNA repair [49]. Doxorubicin is metabolized in the liver by the phase I enzymes aldoketoreductases and carbonyl reductases to an active metabolite, doxorubicinol which is then detoxified by phase II GSTs. Gor et al. [36] examined the impact of variation in CYP3A4, CYP3A5, CYP2B6, CYP2D6, CYP2C9, GSTP1, GSTM1, and GSTT1 and found that women carrying at least one $C Y P 3 A 4 * 1 B$ variant allele (rs2740574) had significantly shorter disease-free survival than wild-type women. The same variants were examined by Yao et al. [40], and they were not able to reproduce this association. Another study found that variants in CYP2B6 (rs192709 and rs3211371) were associated with an increased risk of dose delay in women receiving $\mathrm{AC}$ (doxorubicin, cyclophosphamide) chemotherapy. Other SNPs in this same gene (rs8192709, rs3745274, rs2279343) were associated with worse outcome [37]. Our study found that variation in $C Y P 2 B 6$ did not modify the effect of $\mathrm{FAC} / \mathrm{FEC}$ on risk of $\mathrm{CBC}$.

Doxorubicin and MTX are also substrates of P-glycoprotein, an efflux transporter that is the product of the $A B C B 1$ [multi-drug resistance $(M D R-1)$ ] gene (reviewed in [50, 51]). Lal et al. [52] found that SNPs in $A B C B 1$ increased drug exposure by decreasing its clearance. Variation in $A B C B 1$ has also been associated with clinical response and overall survival in women receiving doxorubicin-based chemotherapy [53-55]. Studies examining the impact of variation in GSTP1 have been mixed [56, 57].

The strengths of this study include the population-based design, the large number of women with $\mathrm{CBC}$, enabling the examination of $\mathrm{CBC}$ as an outcome, and the extensive review of patient medical records and questionnaire data, to obtain detailed treatment information. A limitation of the tagSNP approach used here is that it does not address the impact of less common or rare variants (MAF $<5 \%$ ), SNPs not in LD with typed variants, insertions/deletions, epigenetic modifications, and copy number variations, on treatment response. Further, complete gene coverage was not achieved for all genes, and in some cases, a candidate SNP approach was used (e.g., CYP1A1). It is possible that un-typed variants in these candidate genes and variation in genes not included in the current analysis could modify the effect of treatment on risk of CBC. A further limitation of this study is that for variants with a low minor allele frequency or modest effects on the association between chemotherapy and risk of $\mathrm{CBC}$, our power is reduced.

\section{Conclusion}

This is the first study to specifically address the impact of germline genetic variation on the association between chemotherapy and risk of $\mathrm{CBC}$. The results of this study suggest that chemotherapy (CMF and FAC/FEC) is associated with a lower risk of $\mathrm{CBC}$ regardless of genetic variation in selected genes that code for proteins involved in the metabolism of these commonly used chemotherapeutic agents.

Acknowledgments This work was supported by National Cancer Institute (R03CA139583, R01CA097397, U01 CA083178, R01 CA129639). We thank the women who participated in the WECARE Study. 
Open Access This article is distributed under the terms of the Creative Commons Attribution License which permits any use, distribution, and reproduction in any medium, provided the original author(s) and the source are credited.

\section{Appendix: The WECARE Study Collaborative Group}

Memorial Sloan-Kettering Cancer Center (New York, NY): Jonine L. Bernstein Ph.D. (WECARE Study P.I.), Colin Begg. Ph.D., Jennifer D. Brooks Ph.D., Marinela Capanu Ph.D., Xiaolin Liang M.D., Anne S. Reiner M.P.H., Irene Orlow Ph.D, Robert Klein Ph.D. (Coinvestigator), Ken Offit M.D. (Co-investigator); Meghan Woods M.P.H.;

Beckman Research Institute, City of Hope National Medical Center (Duarte, CA): Leslie Bernstein Ph.D. (subcontract P.I.);

Cancer Prevention Institute of California (Fremont, CA): Esther M. John Ph.D. (Sub-contract PI);

Danish Cancer Society (Copenhagen, Denmark): Jørgen H. Olsen M.D. DMSc. (Sub-contract P.I.), Lene Mellemkjær Ph.D.;

Fred Hutchinson Cancer Research Center (Seattle, WA):

Kathleen E. Malone Ph.D. (Sub-contract P.I.);

National Cancer Institute (Bethesda, MD): Daniela Seminara Ph.D. M.P.H;

National Council on Radiation Protection and Measurements (Bethesda, MD) and Vanderbilt University (Nashville, TN): John D. Boice Jr. Sc.D. (Sub-contract P.I.);

New York University (New York, NY): Roy E. Shore Ph.D., Dr. P.H. (Sub-contract P.I.);

Samuel Lunenfeld Research Institute, Mount Sinai Hospital (Toronto, Canada): Julia Knight, Ph.D. (Subcontract P.I.), Anna Chiarelli Ph.D. (Co-Investigator);

Stanford School of Medicine (Stanford, CA): Robert W. Haile Dr. P.H. (Sub-contract P.I.), Anh T. Diep (CoInvestigator), Nianmin Zhou, M.D.;

Translational Genomics Research Institute (TGen) (Phoenix, AZ): David Duggan Ph.D. (Sub-contract P.I.);

University of Florida (Gainesville, FA): Patrick Concannon, Ph.D. (Sub-contract P.I.), Sharon Teraoka, Ph.D. (Co-Investigator);

University of Iowa (Iowa City, IA): Charles F. Lynch M.D., Ph.D. (Sub-contract P.I.), Michele West, Ph.D.;

University of Southern California (Los Angeles, CA): Daniel Stram Ph.D. (Sub-contract P.I.), Duncan C. Thomas Ph.D. (Co-Investigator), Dave Conti Ph.D., Shanyan Xue M.D., Evgenia Ter-Karapetova;

University of Texas, M.D. Anderson Cancer Center (Houston, TX): Marilyn Stovall Ph.D. (Sub-contract P.I.), Susan Smith M.P.H. (Co-Investigator).

\section{References}

1. Piccart-Gebhart MJ, Sotiriou C (2007) Adjuvant chemotherapyyes or no? Prognostic markers in early breast cancer. Ann Oncol 18 (suppl 12):xii2-xii7. doi:10.1093/annonc/mdm532

2. Early Breast Cancer Trialists' Collaborative Group (2008) Adjuvant chemotherapy in oestrogen-receptor-poor breast cancer: patient-level meta-analysis of randomised trials. Lancet 371(9606):29-40. doi:10.1016/s0140-6736(08)60069-0

3. Levine MN, Pritchard KI, Bramwell VHC, Shepherd LE, Tu D, Paul N (2005) Randomized trial comparing cyclophosphamide, epirubicin, and fluorouracil with cyclophosphamide, methotrexate, and fluorouracil in premenopausal women with node-positive breast cancer: update of National Cancer Institute of Canada Clinical Trials Group Trial MA5. J Clin Oncol 23(22):51665170. doi:10.1200/jco.2005.09.423

4. Martin M, Villar A, Sole-Calvo A, Gonzalez R, Massuti B, Lizon J, Camps C, Carrato A, Casado A, Candel MT, Albanell J, Aranda J, Munarriz B, Campbell J, Diaz-Rubio E (2003) Doxorubicin in combination with fluorouracil and cyclophosphamide (i.v. FAC regimen, day 1,21$)$ versus methotrexate in combination with fluorouracil and cyclophosphamide (i.v. CMF regimen, day 1,21) as adjuvant chemotherapy for operable breast cancer: a study by the GEICAM group. Ann Oncol 14(6):833-842. doi:10.1093/annonc/mdg260

5. EarlyBreastCancerTrialists' Collaborative G (2012) Comparisons between different polychemotherapy regimens for early breast cancer: meta-analyses of long-term outcome among 100000 women in 123 randomised trials. Lancet 379(9814):432-444. doi: 10.1016/s0140-6736(11)61625-5

6. Early Breast Cancer Trialists' Collaborative Group (2005) Effects of chemotherapy and hormonal therapy for early breast cancer on recurrence and 15-year survival: an overview of the randomised trials. Lancet 365(9472):1687-1717

7. Bertelsen L, Bernstein L, Olsen JH, Mellemkjaer L, Haile RW, Lynch CF, Malone KE, Anton-Culver H, Christensen J, Langholz B, Thomas DC, Begg CB, Capanu M, Ejlertsen B, Stovall M, Boice JD Jr, Shore RE, The Women's Environment C, Radiation Epidemiology Study Collaborative Group, Bernstein JL (2008) Effect of systemic adjuvant treatment on risk for contralateral breast cancer in the women's environment, cancer and radiation epidemiology study. J Natl Cancer Inst 100 (1):32-40. doi:10.1093/jnci/djm267

8. Bernstein JL, Thompson DW, Risch N, Holford TR (1992) Risk factors predicting the incidence of second primary breast cancer among women diagnosed with a first primary breast cancer. Am J Epidemiol 136(8):925-936

9. Broët $\mathrm{P}$, de la Rochefordière A, Scholl SM, Fourquet A, Mosseri V, Durand JC, Pouillart P, Asselain B (1995) Contralateral breast cancer: annual incidence and risk parameters. J Clin Oncol 13(7):1578-1583

10. Horn PL, Thompson WD (1988) Risk of contralateral breast cancer: associations with factors related to initial breast cancer. Am J Epidemiol 128(2):309-323

11. Schaapveld M, Visser O, Louwman WJ, Willemse PHB, de Vries EGE, van der Graaf WTA, Otter R, JCoebergh AWW, van Leeuwen FE FE (2008) The impact of adjuvant therapy on contralateral breast cancer risk and the prognostic significance of contralateral breast cancer: a population based study in the Netherlands. Breast Cancer Res Treat 110(1):189-197

12. Reding K, Bernstein J, Langholz B, Bernstein L, Haile R, Begg C, Lynch C, Concannon P, Borg A, Teraoka S, Törngren T, Diep A, Xue S, Bertelsen L, Liang X, Reiner A, Capanu M, Malone K (2010) Adjuvant systemic therapy for breast cancer in BRCA1/ BRCA2; mutation carriers in a population-based study of risk of contralateral breast cancer. Breast Cancer Res Treat 123(2):491498. doi:10.1007/s10549-010-0769-3 
13. Ekhart C, Rodenhuis S, Smits PHM, Beijnen JH, Huitema ADR (2009) An overview of the relations between polymorphisms in drug metabolising enzymes and drug transporters and survival after cancer drug treatment. Cancer Treat Rev 35(1):18-31. doi: 10.1016/j.ctrv.2008.07.003

14. Gonzalez-Neira A (2012) Pharmacogenetics of chemotherapy efficacy in breast cancer. Pharmacogenomics 13(6):677-690

15. Wiechec E, Hansen LL (2009) The effect of genetic variability on drug response in conventional breast cancer treatment. Eur $\mathbf{J}$ Pharmacol 625(1-3):122-130. doi:10.1016/j.ejphar.2009.08.045

16. Bernstein J, Langholz B, Haile R, Bernstein L, Thomas D, Stovall M, Malone K, Lynch C, Olsen J, Anton-Culver H, Shore R, Boice J, Berkowitz G, Gatti R, Teitelbaum S, Smith S, Rosenstein B, Borresen-Dale A-L, Concannon P, Thompson WD (2004) Study design: evaluating gene-environment interactions in the etiology of breast cancer-the WECARE Study. Breast Cancer Res 6(3):R199-R214

17. Barrett JC, Fry B, Maller J, Daly MJ (2005) Haploview: analysis and visualization of LD and haplotype maps. Bioinformatics 21(2):263-265. doi:10.1093/bioinformatics/bth457

18. Gabriel SB, Schaffner SF, Nguyen H, Moore JM, Roy J, Blumenstiel B, Higgins J, DeFelice M, Lochner A, Faggart M, LiuCordero SN, Rotimi C, Adeyemo A, Cooper R, Ward R, Lander ES, Daly MJ, Altshuler D (2002) The structure of haplotype blocks in the human genome. Science 296(5576):2225-2229. doi: 10.1126/science.1069424

19. Teraoka S, Bernstein J, Reiner A, Haile R, Bernstein L, Lynch C, Malone K, Stovall M, Capanu M, Liang X, Smith S, Mychaleckyj J, Hou X, Mellemkjaer L, Boice J, Siniard A, Duggan D, Thomas D, The WECARE Study Collaborative Group, Concannon P (2011) Single nucleotide polymorphisms associated with risk for contralateral breast cancer in the Women's Environment, Cancer, and Radiation Epidemiology (WECARE) Study. Breast Cancer Res 13 (6):R114

20. Hersberger M, Marti-Jaun J, Rentsch K, Hänseler E (2000) Rapid detection of the CYP2D6*3, CYP2D6*4, and CYP2D6*6 alleles by tetra-primer PCR and of the CYP2D6*5 allele by multiplex long PCR. Clin Chem 46(8):1072-1077

21. Price AL, Patterson NJ, Plenge RM, Weinblatt ME, Shadick NA, Reich D (2006) Principal components analysis corrects for stratification in genome-wide association studies. Nat Genet 38(8):904-909. doi:http://www.nature.com/ng/journal/v38/n8/ suppinfo/ng1847_S1.html

22. Purcell S, Neale B, Todd-Brown K, Thomas L, Ferreira MAR, Bender D, Maller J, Sklar P, de Bakker PIW, Daly MJ, Sham PC (2007) PLINK: a tool set for whole-genome association and population-based linkage analyses. Am J Hum Genet 81(3):559-575

23. de Jonge ME, Huitema ADR, Rodenhuis S, Beijnen JH (2005) Clinical pharmacokinetics of cyclophosphamide. Clin Pharmacokinet 44(11):1135-1164

24. Chang TKH, Weber GF, Crespi CL, Waxman DJ (1993) Differential activation of cyclophosphamide and ifosphamide by cytochromes P-450 2B and $3 \mathrm{~A}$ in human liver microsomes. Cancer Res 53(23):5629-5637

25. Chang TKH, Yu L, Goldstein JA, Waxman DJ (1997) Identification of the polymorphically expressed CYP2C19 and the wildtype CYP2C9-ILE ${ }^{359}$ allel as low- $\mathrm{K}_{\mathrm{m}}$ catalysts of cyclophosphamide and ifosfamide activation. Pharmacogenetics 7:211-221

26. Roy P, Yu LJ, Crespi CL, Waxman DJ (1999) Development of a substrate-activity based approach to identify the major human liver P-450 catalysts of cyclophosphamide and ifosfamide activation based on cDNA-expressed activities and liver microsomal P-450 profiles. Drug Metab Dispos 27(6):655-666

27. Xie HJ, Yasar U, Lundgren S, Griskevicius L, Terelius Y, Hassan M, Rane A (2003) Role of polymorphic human CYP2B6 in cyclophosphamide bioactivation. Pharmacogenomics J 3(1):53-61
28. Dirven HAAM, van Ommen B, van Bladeren PJ (1996) Glutathione conjugation of Alkylating Cytostatic Drugs with a Nitrogen Mustard Group and the role of glutathione S-transferases. Chem Res Toxicol 9(2):351-360. doi:10.1021/tx950143c

29. Timm R, Kaiser R, Lotsch J, Heider U, Sezer O, Weisz K, Montemurro M, Roots I, Cascorbi I (2005) Association of cyclophosphamide pharmacokinetics to polymorphic cytochrome P450 2C19. Pharmacogenomics J 5(6):365-373

30. Helsby NA, Hui C-Y, Goldthorpe MA, Coller JK, Soh MC, Gow PJ, De Zoysa JZ, Tingle MD (2010) The combined impact of CYP2C19 and CYP2B6 pharmacogenetics on cyclophosphamide bioactivation. $\mathrm{Br} \mathrm{J}$ Clin Pharmacol 70(6):844-853. doi: 10.1111/j.1365-2125.2010.03789.x

31. Petros WP, Hopkins PJ, Spruill S, Broadwater G, Vredenburgh JJ, Colvin OM, Peters WP, Jones RB, Hall J, Marks JR (2005) Associations Between Drug Metabolism Genotype, Chemotherapy Pharmacokinetics, and Overall Survival in Patients With Breast Cancer. J Clin Oncol 23(25):6117-6125. doi:10.1200/ jco.2005.06.075

32. Ambrosone CB, Sweeney C, Coles BF, Thompson PA, McClure GY, Korourian S, Fares MY, Stone A, Kadlubar FF, Hutchins LF (2001) Polymorphisms in glutathione s-transferases (GSTM1 and GSTT1) and survival after treatment for breast cancer. Cancer Res 61(19):7130-7135

33. Yang G, Shu X-O, Ruan Z-X, Cai Q-Y, Jin F, Gao Y-T, Zheng W (2005) Genetic polymorphisms in glutathione-S-transferase genes (GSTM1, GSTT1, GSTP1) and survival after chemotherapy for invasive breast carcinoma. Cancer 103(1):52-58. doi:10.1002/ cncr.20729

34. Sweeney C, McClure GY, Fares MY, Stone A, Coles BF, Thompson PA, Korourian S, Hutchins LF, Kadlubar FF, Ambrosone CB (2000) Association between survival after treatment for breast cancer and glutathione S-transferase P1 Ile105Val polymorphism. Cancer Res 60(20):5621-5624

35. Sweeney C, Ambrosone CB, Joseph L, Stone A, Hutchins LF, Kadlubar FF, Coles BF (2003) Association between a glutathione S-transferase A1 promoter polymorphism and survival after breast cancer treatment. Int $\mathrm{J}$ Cancer 103(6):810-814. doi: 10.1002/ijc. 10896

36. Gor P, Su HI, Gray R, Gimotty P, Horn M, Aplenc R, Vaughan W, Tallman M, Rebbeck T, DeMichele A (2010) Cyclophosphamide- metabolizing enzyme polymorphisms and survival outcomes after adjuvant chemotherapy for node-positive breast cancer: a retrospective cohort study. Breast Cancer Res 12(3):R26

37. Bray J, Sludden J, Griffin MJ, Cole M, Verrill M, Jamieson D, Boddy AV (2010) Influence of pharmacogenetics on response and toxicity in breast cancer patients treated with doxorubicin and cyclophosphamide. $\mathrm{Br} \quad \mathrm{J}$ Cancer 102(6):1003-1009. doi: http://www.nature.com/bjc/journal/v102/n6/suppinfo/6605587s1. html

38. Bewick MA, Conlon MSC, Lafrenie RM (2008) Polymorphisms in manganese superoxide dismutase, myeloperoxidase and glutathione-S-transferase and survival after treatment for metastatic breast cancer. Breast Cancer Res Treat 111:93-101

39. Ekhart C, Doodeman VD, Rodenhuis S, Smits PHM, Beijnen JH, Huitema ADR (2008) Influence of polymorphisms of durg metabolizing enzymes (CYP2B6, CYP2C9, CYP2C19, CYP3A4, CYP3A5, GSTA1, GSTP1, ALDH1A1 and ALDH3A1) on the pharmacokinetics of cyclophosphamide and 4-hydroxycyclophosphamide. Pharmacogenet Genomics 18:515-523

40. Yao S, Barlow WE, Albain KS, Choi J-Y, Zhao H, Livingston RB, Davis W, Rae JM, Yeh I-T, Hutchins LF, Ravdin PM, Martino S, Lyss AP, Osborne CK, Abeloff M, Hortobagyi GN, Hayes DF, Ambrosone CB (2010) Gene polymorphisms in cyclophosphamide metabolism pathway, treatment-related toxicity, and disease-free 
survival in SWOG 8897 clinical trial for breast cancer. Clin Cancer Res 16(24):6169-6176. doi:10.1158/1078-0432.ccr-10-0281

41. Thorn CF, Marsh S, Whirl Carrillo M, McLeod HL, Klein TE, Altman RB (2011) PharmGKB summary: fluoropyrimidine pathways. Pharmacogenet Genomics 21:237-242

42. Ulrich CM, Robien K, McLeod HL (2003) Cancer pharmacogenetics: polymorphisms, pathways and beyond. Nat Rev Cancer 3(12):912-920

43. Sohn K-J, Croxford R, Yates Z, Lucock M, Kim Y-I (2004) Effect of the methylenetetrahydrofolate reductase C677T polymorphism on chemosensitivity of colon and breast cancer cells to 5-fluorouracil and methotrexate. J Natl Cancer Inst 96(2):134144. doi:10.1093/jnci/djh015

44. Shrubsole M, Shu X, Ruan Z, Cai Q, Cai H, Niu Q, Gao Y-T, Zheng W (2005) MTHFR genotypes and breast cancer survival after surgery and chemotherapy: a report from the Shanghai Breast Cancer Study. Breast Cancer Res Treat 91(1):73-79. doi: 10.1007/s10549-004-7265-6

45. Zhang W, Press OA, Haiman CA, Yang DY, Gordon MA, Fazzone W, El-khoueiry A, Iqbal S, Sherrod AE, Lurje G, Lenz H-J (2007) Association of methylenetetrahydrofolate reductase gene polymorphisms and sex-specific survival in patients with metastatic colon cancer. J Clin Oncol 25(24):3726-3731. doi: 10.1200/jco.2007.11.4710

46. Cohen V, Panet-Raymond V, Sabbaghian N, Morin I, Batist G, Rozen R (2003) Methylenetetrahydrofolate reductase polymorphism in advanced colorectal cancer. Clin Cancer Res 9(5):16111615

47. Etienne M-C, Formento J-L, Chazal M, Francoual M, Magné N, Formento P, Bourgeon A, Seitz J-F, Delpero J-R, Letoublon C, Pezet D, Milano G (2004) Methylenetetrahydrofolate reductase gene polymorphisms and response to fluorouracil-based treatment in advanced colorectal cancer patients. Pharmacogenetics 14(12):785-792

48. Paré L, Altés A, Cajal TRy, Del Rio E, Alonso C, Sedano L, Barnadas A, Baiget M (2007) Influence of thymidylate synthase and methylenetetrahydrofolate reductase gene polymorphisms on the disease-free survival of breast cancer patients receiving adjuvant 5-fluorouracil/methotrexate-based therapy. Anticancer Drugs 18(7):821-825

49. Thorn CF, Oshiro C, Marsh S, Hernandez-Boussard T, McLeod HL, Klein TE, Altman RB (2011) Doxorubicin pathways: pharmacodynamics and adverse effects. Pharmacogenet Genomics 21:440-446

50. Mechetner E, Kyshtoobayeva A, Zonis S, Kim H, Stroup R, Garcia R, Parker RJ, Fruehauf JP (1998) Levels of multidrug resistance (MDR1) P-glycoprotein expression by human breast cancer correlate with in vitro resistance to taxol and doxorubicin. Clin Cancer Res 4(2):389-398

51. Mikkelsen TS, Thorn CF, Yang JJ, Ulrich CM, French D, Zaza G, Dunnenberger HM, Marsh S, McLeod HL, Giacomoni K, Becker ML, Gaedigk R, Leeder JS, Kager L, Relling MV, Evans W, Klein TE, Altman RB (2011) PharmGKB summary: methotrexate pathway. Pharmacogenet Genomics 21:679-686

52. Lal S, Wong ZW, Sandanaraj E, Xiang X, Ang PCS, Lee EJD, Chowbay B (2008) Influence of ABCB1 and ABCG2 polymorphisms on doxorubicin disposition in Asian breast cancer patients. Cancer Sci 99(4):816-823. doi:10.1111/j.1349-7006. 2008.00744.x

53. Kafka A, Sauer G, Jaeger C, Kreienberg R, Zeillinger R, Deissler H (2003) Polymorphism C3435T of the MDR-1 gene predicts response to preoperative chemotherapy in locally advanced breast cancer. Int J Oncol 22:1117-1121

54. Nordgard S, Ritchie M, Jensrud S, Motsinger A, Alnaes G, Lemmon G, Berg M, Geisler S, Moore J, Lonning P, BorresenDale A, Kristensen V (2007) ABCB1 and GST polymorphisms associated with TP53 status in breast cancer. Pharmacogenet Genomics 17:127-136

55. Wu H, Kang H, Liu Y, Tong W, Liu D, Yang X, Lian M, Yao W, Zhao H, Huang D, Sha X, Wang E, Wei M Roles of $A B C B 1$ gene polymorphisms and haplotype in susceptibility to breast carcinoma risk and clinical outcomes. J Cancer Res Clin Oncol:1-14. doi:10.1007/s00432-012-1209-z

56. Romero A, Martín M, Oliva B, de la Torre J, Furio V, de la Hoya M, García-Sáenz JA, Moreno A, Román JM, Diaz-Rubio E, Caldés T (2011) Glutathione S-transferase P1 c.313A $>$ G polymorphism could be useful in the prediction of doxorubicin response in breast cancer patients. Ann Oncol. doi:10.1093/ annonc/mdr483

57. Mishra A, Chandra R, Mehrotra P, Bajpai P, Agrawal D (2011) Glutathione $\mathrm{S}$-transferase $\mathrm{M} 1$ and $\mathrm{T} 1$ polymorphism and response to neoadjuvant chemotherapy (CAF) in breast cancer patients. Surg Today 41(4):471-476. doi:10.1007/s00595-0094310-4 